\title{
Sealant Delamination Detection of Structural Sealant Glazing Systems Based on Driving-Point Accelerance
}

\author{
Danguang Pan $\mathbb{D}^{1,2}$ Kun Jiang, ${ }^{1}$ Xichen Zhang, ${ }^{3}$ and Ying Huang ${ }^{4}$ \\ ${ }^{1}$ Department of Civil Engineering, University of Science and Technology Beijing, Beijing 100083, China \\ ${ }^{2}$ Beijing Key Laboratory of Urban Underground Space Engineering, School of Civil and Resource Engineering, \\ University of Science and Technology Beijing, Beijing 100083, China \\ ${ }^{3}$ Center for Curtain Wall and Windows \& Doors Technology, China Academy of Building Research, Beijing 100013, China \\ ${ }^{4}$ Department of Civil and Environmental Engineering, North Dakota State University, Fargo, ND 58108-6050, USA
}

Correspondence should be addressed to Danguang Pan; pdg@ustb.edu.cn

Received 7 October 2019; Revised 24 January 2020; Accepted 4 May 2020; Published 18 May 2020

Academic Editor: Salvatore Caddemi

Copyright (c) 2020 Danguang Pan et al. This is an open access article distributed under the Creative Commons Attribution License, which permits unrestricted use, distribution, and reproduction in any medium, provided the original work is properly cited.

\begin{abstract}
The structural sealant glazing system is widely used in glass curtain wall worldwide. However, due to the aging of the sealants, cracking may form along the sides of the glass. If the panel of curtain wall arises, delamination may occur and induce failure or loss of the system. In order to detect the delamination of the sealant, in this paper, a new vibration-based damage identification method is proposed by using the difference between the predamage and postdamage driving-point accelerance (DA). This detection method would require only one acceleration sensor on a glass panel and a rubber hammer, which operates very conveniently. When the rubber hammer taps the glass panel near the acceleration sensor, the glass curtain wall panel would generate acceleration response which can be measured by the acceleration sensor. The measured acceleration responses will be used to calculate the DA and lead to a new delamination index, called relative accumulative difference of DA, which will give indications on the potential delamination of the sealant. In addition, the influence of the acceleration sensor installation position was analysed by the finite element method, and the optimal sensor location was determined to be at the intersection of the long-side quarter and the short-side quarter. Nine cases on various delamination severities were identified by the new method, as well as the natural frequency reduction and modal assurance criterion. The laboratory experiments showed that the relative accumulative difference of DA is extremely sensitive to sealant delamination. Even if delamination severity was only $6.39 \%$, the relative accumulative difference of DA would be larger than $18 \%$. As the delamination of the sealant progresses, the relative accumulative difference of DA increases, resulting in an effective detection method for sealant delamination of the structural sealant glazing system. The fundamental frequency reduction is suitable to identify relatively large delamination, and the modal assurance criterion of higher modes is also sensitive to sealant delamination.
\end{abstract}

\section{Introduction}

The structural sealant glazing system (SSGS) is widely used in the high-rise buildings and commercial structures since it provides a beautiful appearance for the building. However, due to the aging and fatigue in the service life, the structural sealant may delaminate and fall off resulting in damages in the supporting system of SSGS [1]. To avoid the detachment of the glass curtain wall panel, it is of great importance to detect the sealant delamination and repair it timely [2-5].
To detect the sealant delamination, there are two types of methods available, including static-based and vibrationbased method. The static-based detection method is used relatively earlier, which includes appearance visual inspection, knock detection, cutting and drawing method, shore hardness method, suction lifter, air bag, and pulse echo ultrasonic testing [6-10]. The visual and knock methods are simple but can only be used as the preliminary testing of the delamination of structural sealant, whose accuracy depends on the experiences of the inspectors [11]. Cutting and drawing method is to bring the cut part of the sample back to 
the laboratory for testing. This method would induce damage to the structure which is a destructive testing method. Shore hardness method detects the degree of hardening of structural sealant, which needs to be combined with other methods together to identify damages [12]. Air bag method needs the displacement measuring equipment to detect. Suction lifter method belongs to outdoor detection, which is usually used to detect the adhesion of the glass curtain wall just for double glazing [13]. Recently, Hong et al. [14-16] used the thermal wave and ultrasonic wave to detect structural sealant damage directly and visually. Static-based detection method usually requires location where workers can reach, and the testing labor is huge.

For the vibration-based method, which was firstly developed in bridge engineering, delamination is detected by measuring the changes in dynamic characteristics or dynamic response of the system, such as natural frequency, mode shapes, mode shape curvature, waveform chain code, and signature assurance criteria [17-24]. Memari et al. [25] developed kinematic-based models to predict earthquakeinduce failure of the SSGS. Puga et al. [26] studied the glass failure mechanisms of glass panels with different thicknesses, as well as assessed their probability of failure by estimating fragility curves. Carolina et al. [27] analysed the cyclic response of a glass curtain wall for seismic performance assessment. Xu et al. [28] used the dynamic response parameters and dynamic characteristics parameters as the input of artificial neural network to identify debonding situation, which can be used as the damage monitoring of several important unit of SSGS. Liu et al. [29, 30] detected natural frequency reduction of the glass curtain wall and related that to the weakening of the boundary conditions. Miao et al. [31] provided a relationship between the ratio of the main peak frequency of the fast Fourier transform to the total power of the signal and damage length of the SSGS. Fang and Luo [32] identified the damage of perimeter sealant by the change in mode shape curvature.

Although delamination of the structural sealant can be identified using the change of predamage and postdamage dynamic characteristics, there are dozens of taps in experimental modal analysis which spend long time to get mode shapes of only one unit of SSGS. For a glass curtain wall building, it usually contains hundreds of independent units, and different parts of the glass curtain wall have different degrees of aging and delamination. It is a tedious work to detect the safety of glass curtain wall. Detecting the delamination fast is a challenge in practical detection. Recently, Huang et al. [33-35] validated in experiments that the change of the fundamental natural frequency can be used to detect damage of the structural sealant and proposed the first peak of acceleration Fourier spectrum as the approximate fundamental frequency to significantly reduce the test time. It is well known that fundamental frequency reflects the overall characters of structures, and it is suitable to identify relatively large delamination; however, local small damage is not easy to be identified [36].

In this paper, a new vibration-based method is developed to identify the delamination of sealants of the SSGS quickly during manual inspection process, even if in the case of small delamination. In this method, a new delamination index is established by using driving-point accelerance (DA) to identify the sealant delamination and approximately estimate the severity of damage. Only one acceleration sensor on a glass panel and a rubber hammer are required and only one driving point should be tapped to measure DA, so the operation of this method is very simple and fast. To improve the effect of sealants delamination on the DA, the optimal sensor location was analysed by the finite element method, and the effect of tapping point from the sensor on the DA was investigated by experiments. Then, nine different delamination cases were carried out in the laboratory to verify the rationality and accuracy of the proposed method. Because each glass panel only needs to be tapped one point, it is very suitable to detect the delamination of SSGS with thousands of units for its less detection time.

\section{Delamination Index Based on Driving- Point Accelerance}

When the sealants of the SSGS is delamination, the boundary conditions of the curtain wall are changed, which cause the corresponding change of dynamic characteristics and dynamic response of the system. DA, which is sensitive to the change of boundary conditions, is used for the delamination of sealants.

Considering the impact hammer load applied to a specific degree of freedom (DOF), the forced vibration equation of an $n$-degree-of-freedom system is [37]

$$
[m]\{a\}+[c]\{v\}+[k]\{u\}=\{f\} p(t)
$$

where $[m]$ is the mass matrix, $[k]$ is coefficient matrix stiffness, and $[c]$ is damping matrix of the glass panel; $p(t)$ is the time history of the hammer load, $\{u\},\{v\}$, and $\{a\}$ are the displacement, velocity, and acceleration vectors; and $\{f\}$ is the force attribution vector. The load are applied to the $r$ th DOF; then, the element of $\{f\}$ is

$$
f_{k}= \begin{cases}1, & k=r, \\ 0, & k \neq r .\end{cases}
$$

Let the first $n$ natural frequencies and associated mode shapes be $\omega_{j}$ and $\left\{\varphi_{j}\right\} \quad(j=1,2, \ldots, n)$. The driving-point accelerance (DA), which is the acceleration frequency response function (FRF) of the $r$ th DOF, can be expressed as follows:

$$
H_{r}(\theta)=\frac{A_{r}(\theta)}{P(\theta)}=-\sum_{j=1}^{n} \frac{\varphi_{r j}^{2} \theta^{2}}{-\theta^{2} m_{j}+i \theta c_{j}+k_{j}},
$$

where $i=\sqrt{-1}, P(\theta)$ and $A_{r}(\theta)$ are the Fourier transforms of $p(t)$ and $a_{r}(t)$, respectively; $a_{r}(t)$ is the acceleration time history of the $r$ th DOF; $m_{j}=\left\{\varphi_{j}\right\}^{\mathrm{T}}[m]\left\{\varphi_{j}\right\}$ is the modal mass; $c_{j}=\left\{\varphi_{j}\right\}^{\mathrm{T}}[c]\left\{\varphi_{j}\right\}$ is the modal damping coefficient; and $k_{j}=\left\{\varphi_{j}\right\}^{\mathrm{T}}[k]\left\{\varphi_{j}\right\}$ is the modal stiffness coefficient; and $\varphi_{r j}$ is the $r$ th element of $\left\{\varphi_{j}\right\}$.

Once the sealants have some delamination, the dynamic characteristics of panel will be changed, leading to the corresponding change of DA generated by the hammer load. 


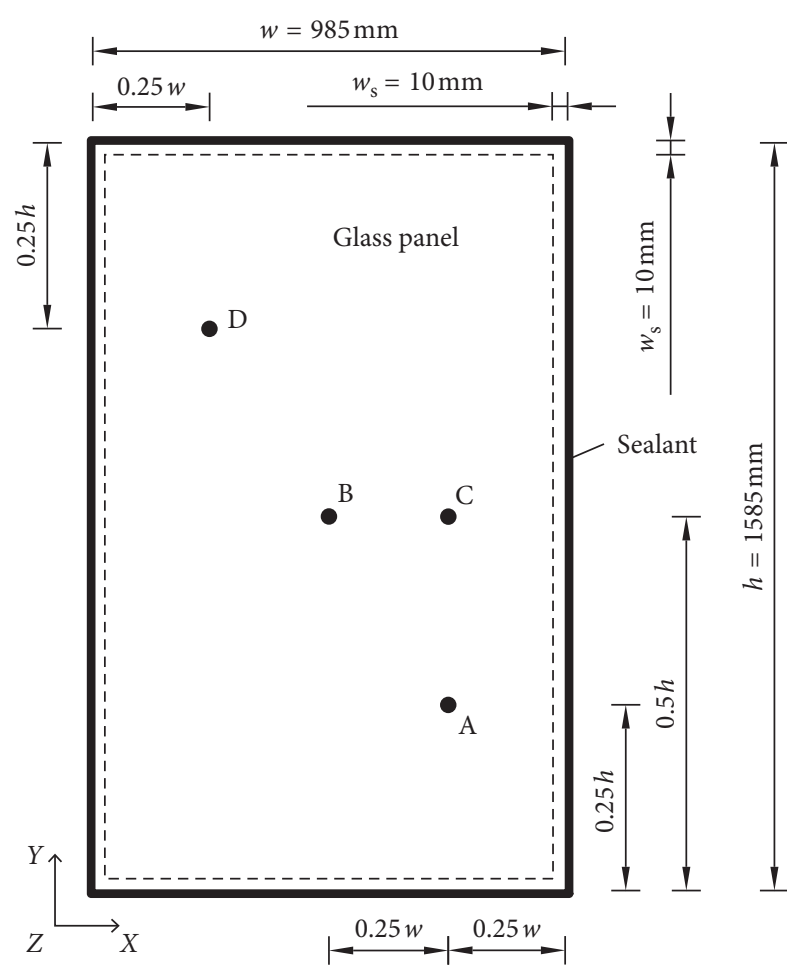

(a)

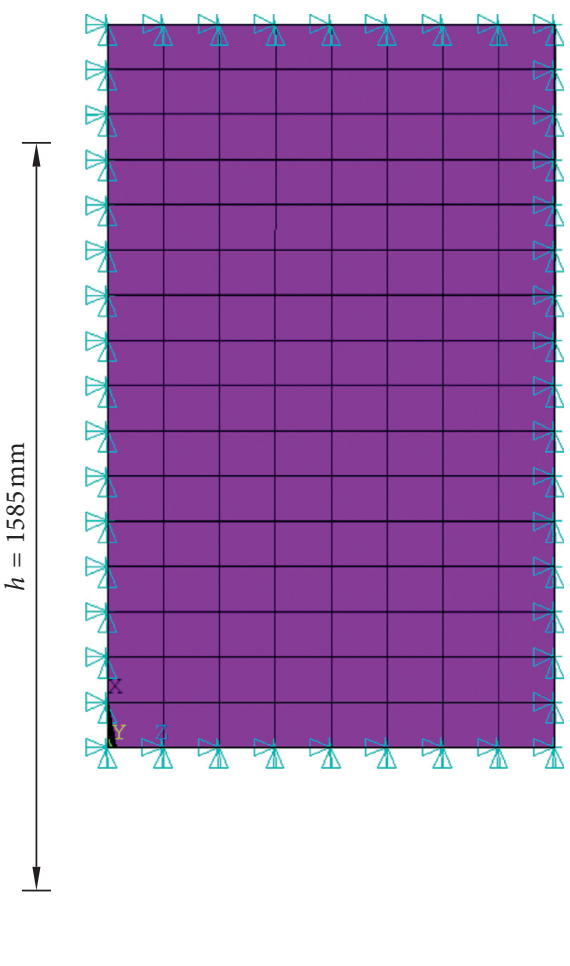

(b)

Figure 1: Model of a panel. (a) Sketch of sensor locations; (b) finite element model.

Therefore, based on the relative changing of predamage and postdamage of DA, the delamination index, called relative accumulation difference $\left(E_{\mathrm{a}}\right)$ of DA, is proposed to detect the delamination as follow:

$$
E_{\mathrm{a}}=\frac{\int_{0}^{\infty}|| H_{r}^{d}(\theta)|-| H_{r}^{u}(\theta)|| \mathrm{d} \theta}{\int_{0}^{\infty}\left|H_{r}^{u}(\theta)\right| \mathrm{d} \theta} \times 100 \%,
$$

where the superscript $u$ and $d$ denote the undamaged and damaged case, respectively. In the practical test, the signals of acceleration and load are discrete signals so that DA is calculated by the discrete Fourier transform (DFT).

From equation (3), it can be seen that the location of acceleration sensor significantly affects DA. Thus, the hammer impact location must be optimized for less error because the theoretical tap location is occupied by the sensor. Therefore, first, investigate the optimized location of acceleration sensor and the effect of the error of hammer impact location and then investigate the accuracy of the delamination index, $E_{\mathrm{a}}$.

\section{Optimization of Acceleration Sensor Location}

In order to optimize the sensor location, numerical analysis was performed using ANSYS on a typical panel, as shown in Figure 1(a), to obtain the mode shapes and frequency responses. The size of the unit was $1585 \mathrm{~mm}$ in height, $985 \mathrm{~mm}$ in width, and $6 \mathrm{~mm}$ in thickness. As shown in Figure 1(b), the panel was divided by shell element into 128 elements with Young's modulus $7.2 \times 10^{4} \mathrm{MPa}$, density $2000 \mathrm{~kg} / \mathrm{m}^{3}$, and Poisson ratio 0.2 . The panel was attached to the support frame by sealant with width $w_{\mathrm{s}}=10 \mathrm{~mm}$ and thickness $h_{\mathrm{s}}=15 \mathrm{~mm}$. Boundary condition was assumed to be simply supported in the $X$ and $Y$ directions, and there was the spring bearing in the $Z$ direction to simulate the effect of sealants. Given Young's modulus $E_{\mathrm{s}}$ of sealant is $0.8 \mathrm{MPa}$, the spring stiffness of sealant per meter was estimated as $k_{\mathrm{s}}=E_{\mathrm{s}} w_{\mathrm{s}} / h_{\mathrm{s}}=533.3 \mathrm{kN} / \mathrm{m}$.

Locations $\mathrm{A}, \mathrm{B}$, and $\mathrm{C}$ (the three locations are representative relatively) in Figure 1(a) were selected as sensor locations to compare the difference of DA with varying sensor locations. Location $\mathrm{A}$ is the intersection of the quarter of long-side and short-side; location $\mathrm{B}$ is the center of the panel; location $\mathrm{C}$ is the intersection between the midpoint of the long-side direction and the quarter of the short side. Figure 2 shows the first 10 modes of vibration from the modal analysis. The DA of the three locations A, B, and C are shown in Figure 3. It can be seen that the DA of location A had six resonance peaks between the frequency range of 0 to $105 \mathrm{~Hz}$, however, that of locations B and C only had three peaks. Comparing with the mode analysis results, it can be seen that the eighth $(95.982 \mathrm{~Hz})$ and ninth $(103.05 \mathrm{~Hz})$ mode shapes did not appear as resonance peaks of the DA of location $\mathrm{A}$ in the first ten natural frequency range, and the resonance peaks of third and fourth and sixth and seventh modes were very close and merge to one. However, only the responses of the first $(19.120 \mathrm{~Hz})$, fourth $(55.099 \mathrm{~Hz})$, and eighth $(95.982 \mathrm{~Hz})$ mode shapes were excited to lead three resonance peaks in the DA of location $\mathrm{B}$. The responses of 


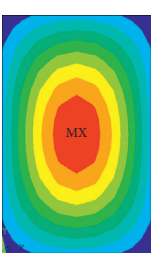

(a)

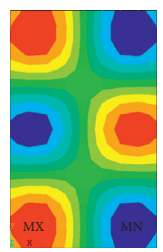

(f)

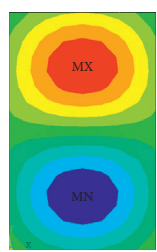

(b)

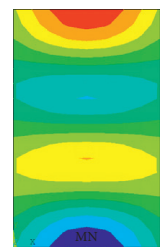

(g)

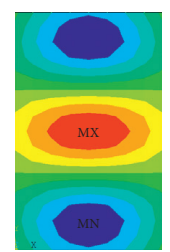

(c)

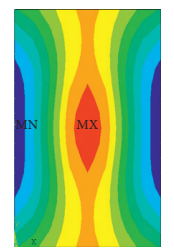

(h)

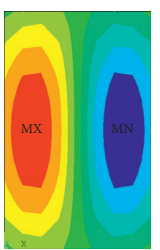

(d)

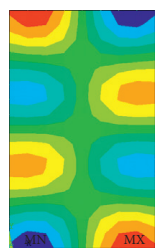

(i)

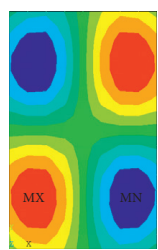

(e)

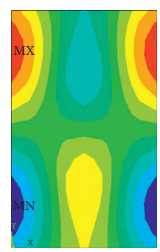

(j)

Figure 2: The first 10 mode shapes and corresponding natural frequencies: (a) the 1st mode $(19.120 \mathrm{~Hz})$; (b) the 2nd mode (32.937 Hz); (c) the 3rd mode $(55.019 \mathrm{~Hz})$; (d) the 4th mode $(55.099 \mathrm{~Hz})$; (e) the 5th mode $(64.120 \mathrm{~Hz})$; (f) the 6th mode $(80.449 \mathrm{~Hz})$; $(\mathrm{g})$ the $7 \mathrm{th} \mathrm{mode}$ $(80.749 \mathrm{~Hz})$; (h) the 8 th mode $(95.982 \mathrm{~Hz})$; (i) the 9th mode $(103.05 \mathrm{~Hz})$; $(\mathrm{j})$ the 10th mode $(104.06 \mathrm{~Hz})$.

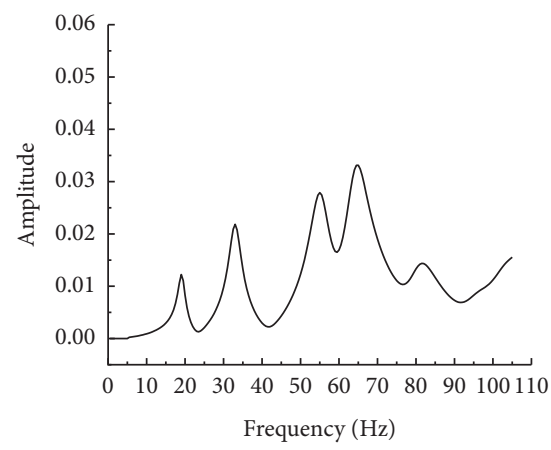

(a)

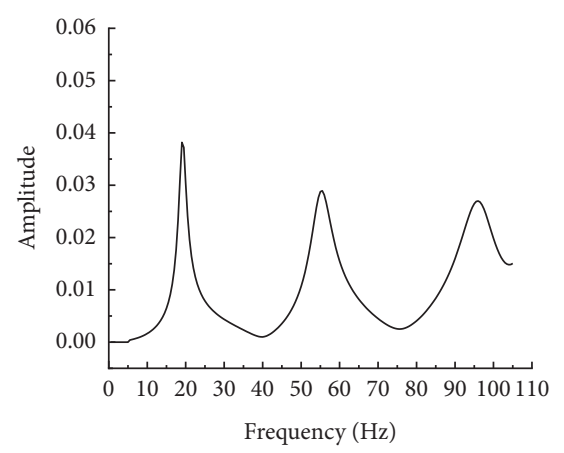

(b)

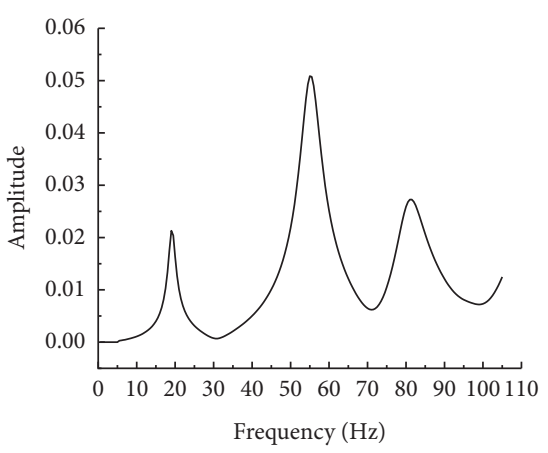

(c)

FIgURE 3: DA at various locations: (a) location A; (b) location B; (c) location C.

the first $(19.120 \mathrm{~Hz})$, fourth $(55.099 \mathrm{~Hz})$, and seventh $(80.749 \mathrm{~Hz})$ mode shapes were excited to lead three resonance peaks in the DA of location C. Since the acceleration sensor should be installed at a location where the most numbers of DA natural mode shapes are obtained, location $A$ is a relative optimal location to install the acceleration sensor. The DA at location A was used to identify the sealant delamination in the further experiments.

\section{Error Analysis of Hammer Impact Location}

4.1. Sample Preparation. The experimental panel was attached to the square steel pipe frame by the sealant, as shown in Figures 4(a) and 4(b). The panel was double glazing comprised of two panels of $6 \mathrm{~mm}$ tempered glass and a gap with $12 \mathrm{~mm}$, and the size of the panel also was $1585 \mathrm{~mm}$ in height and $985 \mathrm{~mm}$ in width. The sealant and the unit should be constructed for three months before test. This was an indoor experiment to research the index itself, so the changes of the external factor were very small that the temperature effect was not considered.
4.2. Experimental Equipment. The type of equipment used in the experiment is shown in Table 1. The equipment was connected together, as shown in Figure 5.

The acceleration sensor was installed at location A using the hot melt adhesive to ensure a proper bonding between glass and sensor. The sampling frequency of test was $2048 \mathrm{~Hz}$. Although the DA calculation requires the impact hammer tapping position and the sensor position to coincide, in the actual test, the impact hammer can only tap the locations near the sensor instead, which would induce systematic errors. At the same time, the arbitrary tapping by operators at the aim point might vary a little bit every time while tapping, which would cause the random error. Figure 6 shows the difference of DA between two times taps for the same aim point. The $E_{\mathrm{a}}$ between the first and second tap is $2.84 \%$, which was denoted that the random error was very small and can be ignored.

An impact hammer generated impacts on several tapping positions, as shown in Figure 7 . The tapping locations were designed to be close to the acceleration sensor (location A, in Figure 7) in the four directions. In each direction, there were six tapping points. The first five 


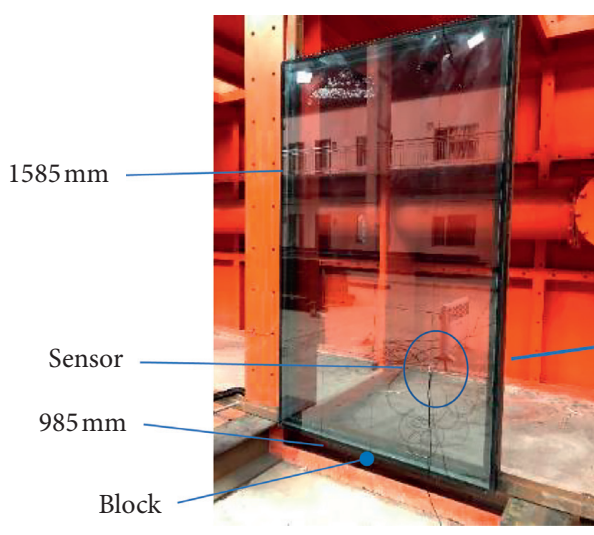

(a)

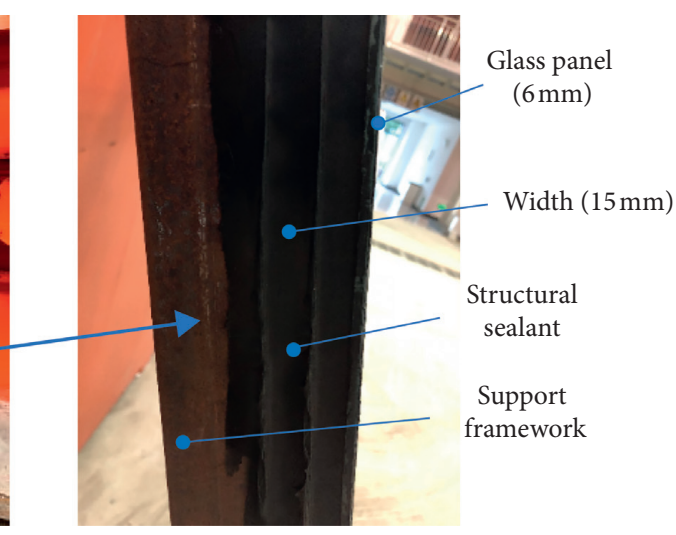

(b)

Figure 4: Experimental sample. (a) Overall sample; (b) local details.

TABle 1: Equipment and type.

\begin{tabular}{lc}
\hline Experiment & Type \\
\hline Impact hammer & DYTRAN-5800B4 \\
Sensor & DYTRAN-3097A2 \\
Data acquisition instrument & COINV-3018A \\
Computer & Lenovo-X201 tablet \\
\hline
\end{tabular}

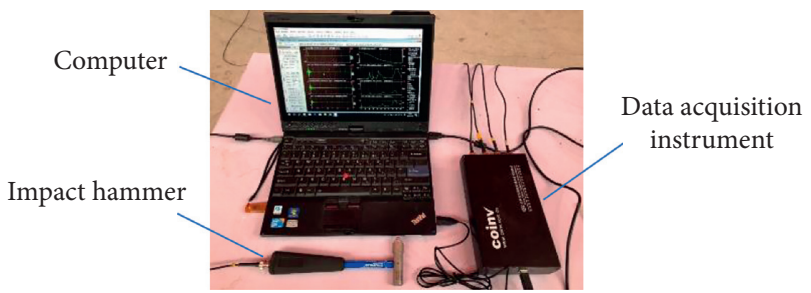

FIgURE 5: Experiment equipment.

points have an interval of $10 \mathrm{~mm}$ in between, and the sixth point has an interval of $50 \mathrm{~mm}$ away from the fifth point. The exact solution was specified as the result of the DA of sensor location A for the four directions. The result is shown in Figure 8 . It can be seen that the $E_{\mathrm{a}}$ along the long-side direction is smaller than the short-side direction due to the fact that the long-side direction is far from the boundary and the short-side boundary is relatively close, which has more influence on the $E_{\mathrm{a}}$. When the excitation point of the impact hammer is controlled within $3 \mathrm{~cm}$ of the distance from the acceleration sensor and is along the long-side direction, the error $E_{\mathrm{a}}$ is lower than $5 \%$.

\section{Delamination Detection}

5.1. Experimental Setup. To validate that the developed technique can detect delamination for the SSGS, nine cases, as shown in Figure 9, were tested. The delamination of the sealant was simulated by cutting. The severity of delamination to the sealant is defined as the ratio between

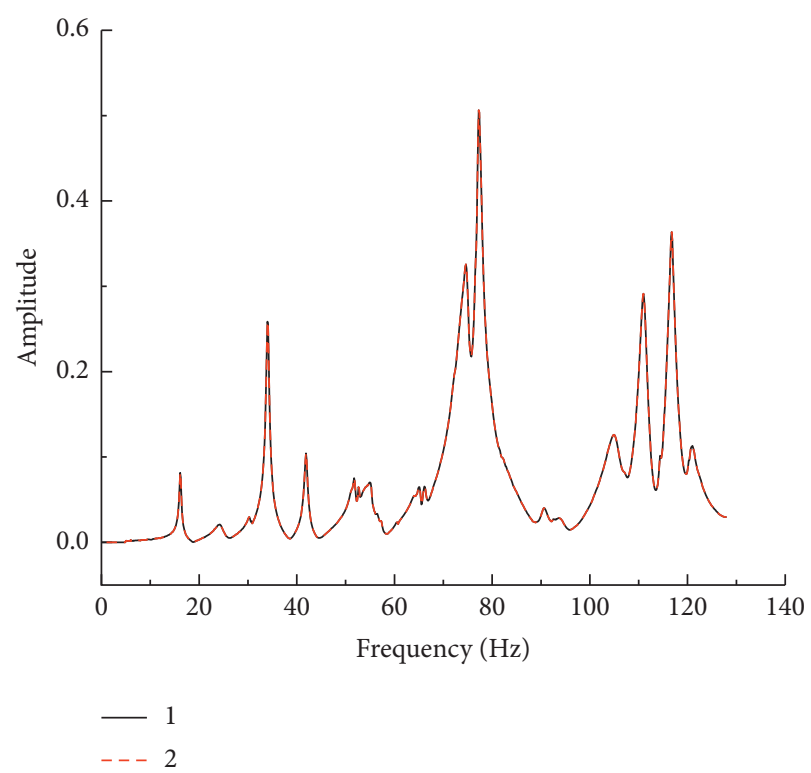

Figure 6: Difference of DA between two times taps for the same aim point.

the failure length $l_{\mathrm{d}}$ and the total length $l_{\mathrm{t}}$ of the sealant, that is,

$$
d=\frac{l_{\mathrm{d}}}{l_{\mathrm{t}}}
$$

The severity of structural sealant delamination in each case is shown in Table 2.

To potentially detect the severity and delamination locations, two acceleration sensors were installed at location A and location $\mathrm{D}$, respectively, which are the intersection of the quarter. Then, the location $\mathrm{A}$ or $\mathrm{D}$ was used as the driving point to illustrate the effect of delamination location on the delamination index. The sampling frequency of the test is $2048 \mathrm{~Hz}$, and then the glass panel was tapped by the impact hammer in the vicinity of the acceleration sensor away from the constraint direction (within $3 \mathrm{~cm}$ ) to control detection error from hammer locations. 


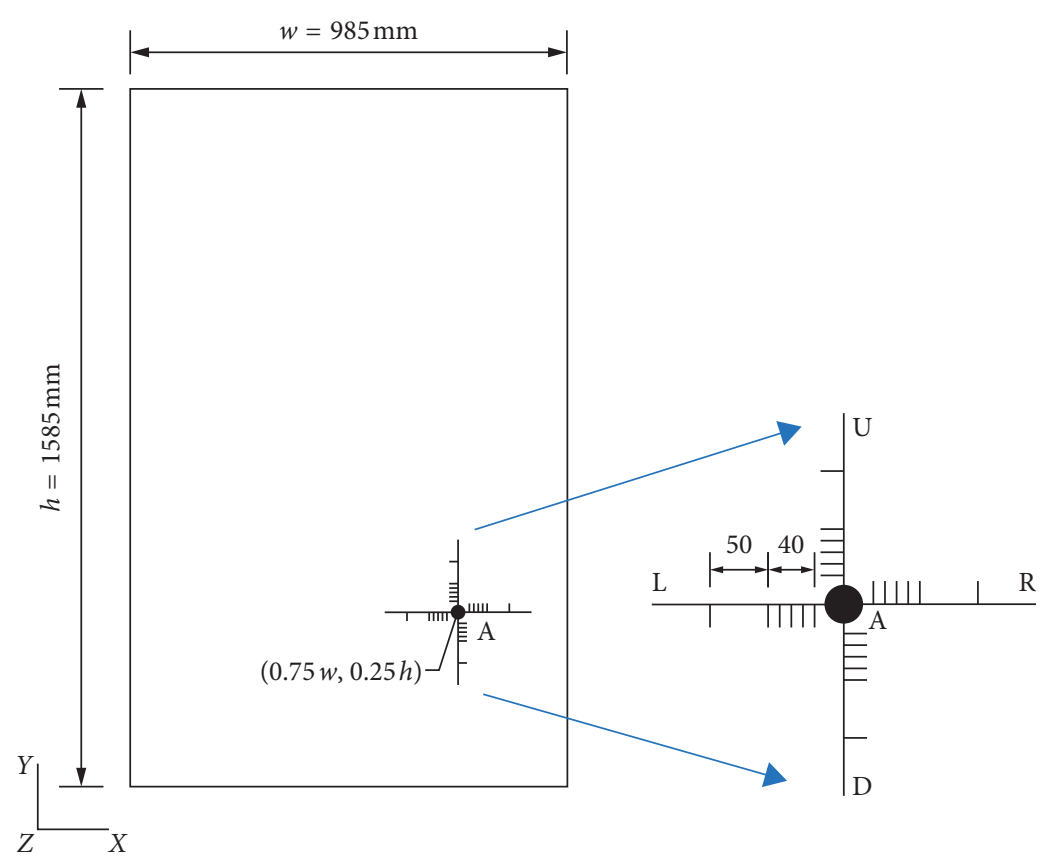

(a)

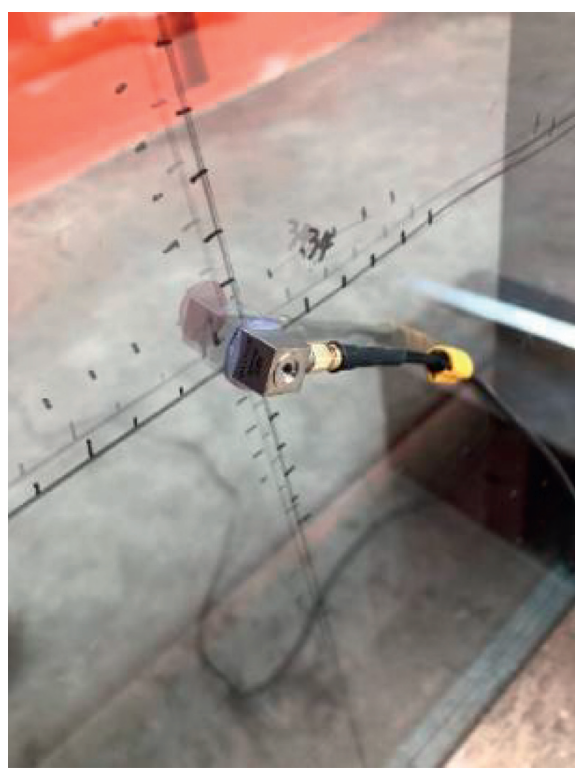

(b)

FIGURE 7: Hammer impact locations: (a) tapping locations (unit: $\mathrm{mm}$ ) and details of point A (unit: $\mathrm{mm}$ ); (b) photo of the experimental setup.

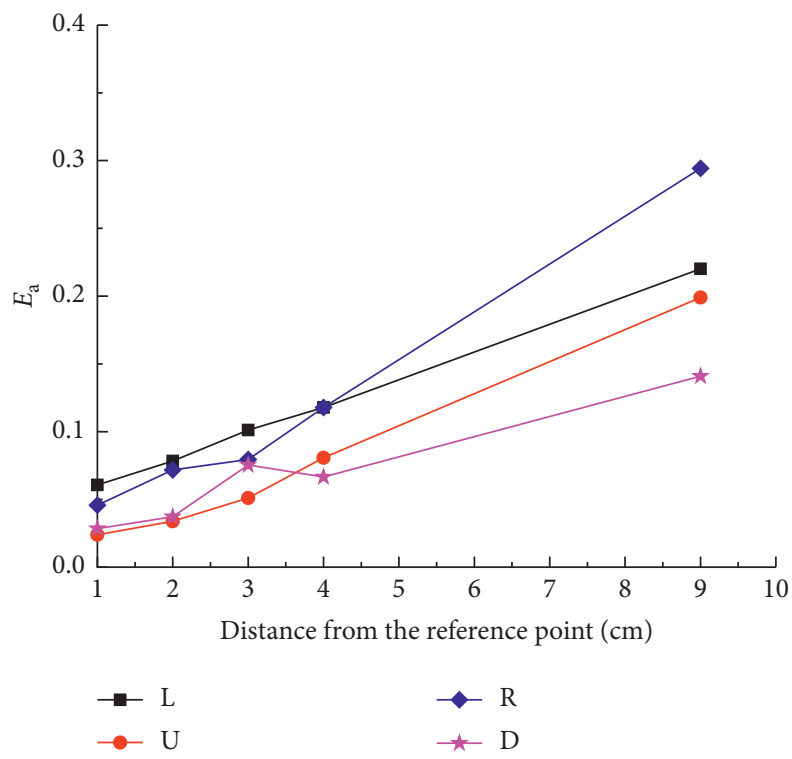

FIgURE 8: $E_{\text {a }}$ of various points.

5.2. Experimental Results. For a distributed parameter system, there are infinite number of the natural frequencies and associated mode shapes. However, relatively few modes can provide sufficiently accurate results in engineering applications. Therefore, through the structural modal parameters to identify the delamination, only a few modes are needed to be considered. The DAs of the nine cases of driving point $\mathrm{A}$ are shown in Figure 10. In each case, the hammer is tapped for three times. The two lines in Figure 10(a) almost coincide for the undamaged case (case 1) DA of arbitrary two test. In Figures 10(b)-10(i), the dashed line is the average DA of the three tests of delaminated case, also shown in solid lines, are the DA of the undamaged case. It can be seen that the differences of DA between damaged cases and undamaged case is more significant with the increasing severity of damage. The DA of case 2 and case 3 is almost the same as that of the case when the frequency is lower than $60 \mathrm{~Hz}$. It means that the effect of the tiny damage on response of low- 


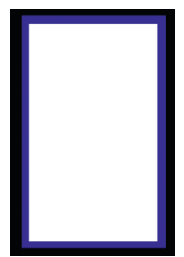

(a)

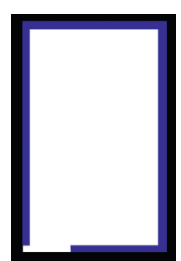

(b)

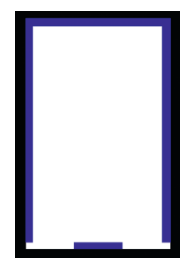

(c)

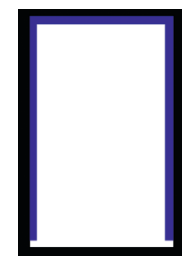

(d)

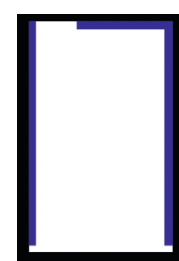

(e)

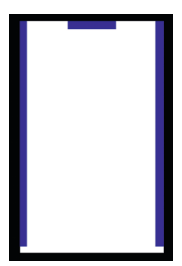

(f)

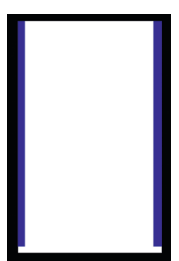

(g)

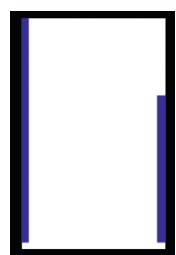

(h)

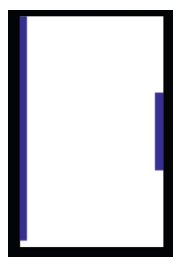

(i)

Figure 9: Perimeter sealant failure illustration of different cases: (a) Case 1; (b) Case 2; (c) Case 3; (d) Case 4; (e) Case 5; (f) Case 6; (g) Case 7; (h) Case 8; (i) Case 9.

TABLE 2: Delamination level.

\begin{tabular}{lccccccccc}
\hline Case & 1 & 2 & 3 & 4 & 5 & 6 & 7 & 8 & 9 \\
\hline Delamination severity (\%) & 0 & 6.39 & 12.78 & 19.16 & 25.55 & 31.94 & 38.33 & 48.61 & 58.89 \\
\hline
\end{tabular}

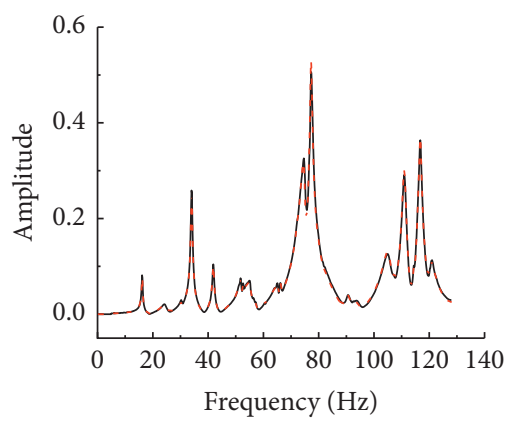

- Case 1 DA of location A -- Case 1 DA of location A

(a)

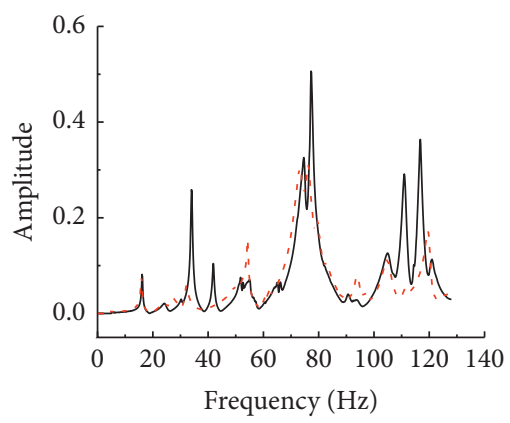

- Case 1 DA of location A

- - - Case 4 DA of location A

(d)

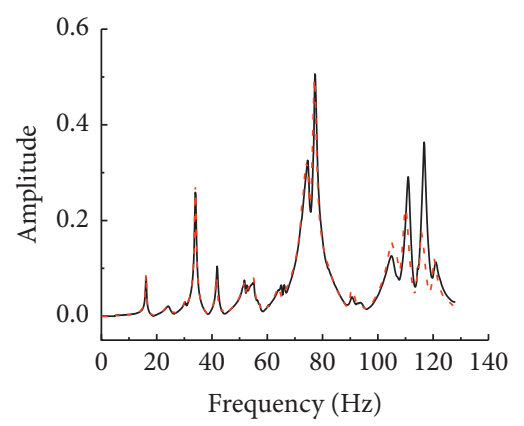

- Case 1 DA of location A

- - Case 2 DA of location A

(b)

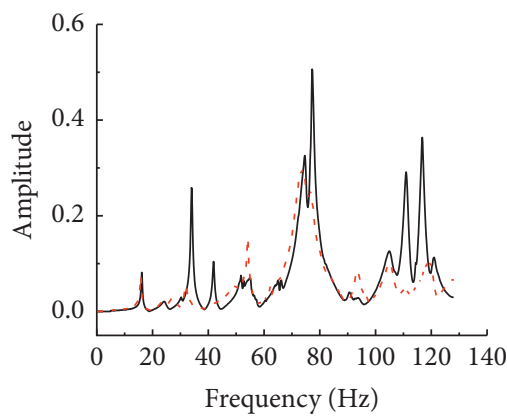

- Case $1 \mathrm{DA}$ of location A

- - Case 5 DA of location A

(e)

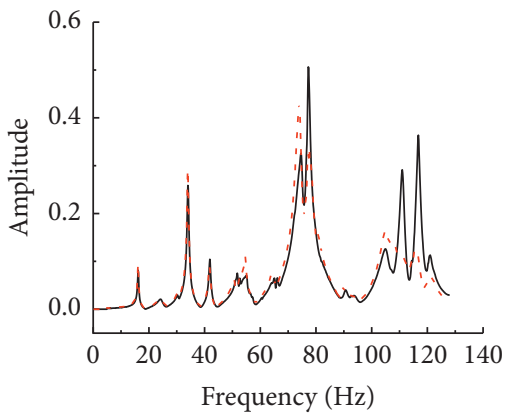

- Case 1 DA of location A

- - Case 3 DA of location A

(c)

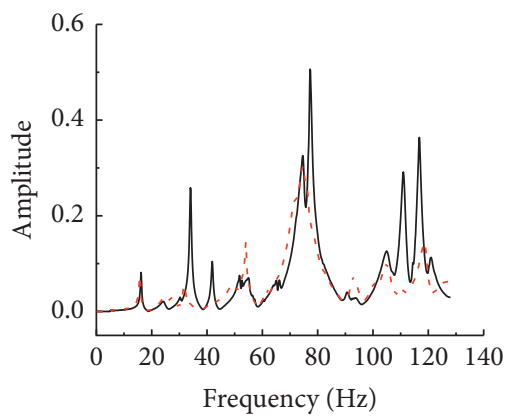

- Case 1 DA of location A

- - - Case 6 DA of location A

(f)

Figure 10: Continued. 


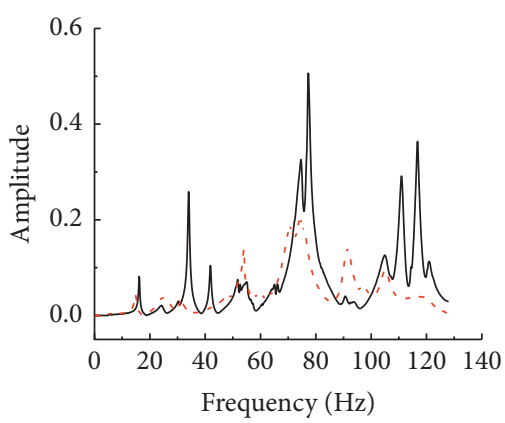

- Case 1 DA of location A

- - - Case 7 DA of location A

(g)

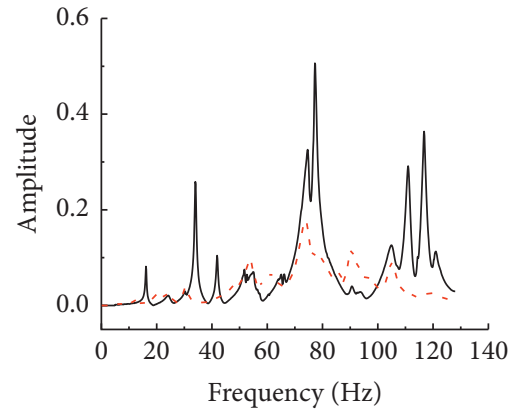

- Case $1 \mathrm{DA}$ of location A

- - - Case 8 DA of location A

(h)

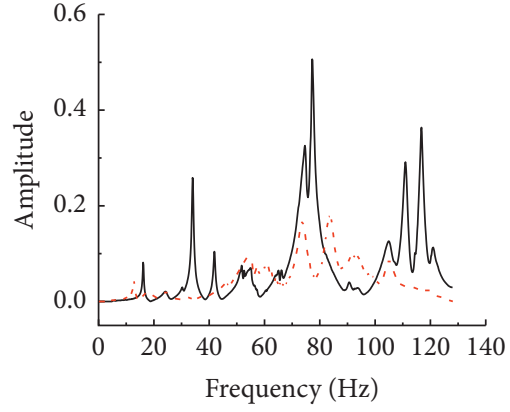

- Case 1 DA of location A

- - - Case 9 DA of location A

(i)

Figure 10: Comparison of DA of driving point A under different cases, (a) 1 vs. 1 ; (b) 1 vs. 2; (c) 1 vs. 3 ; (d) 1 vs. 4 ; (e) 1 vs. 5; (f) 1 vs. 6 ; (g) 1 vs. 7 ; (h) 1 vs. 8 ; (i) 1 vs. 9 .

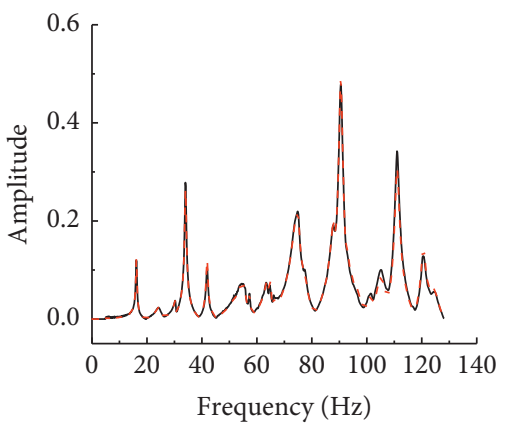

- Case 1 DA of location D - - Case 1 DA of location D

(a)

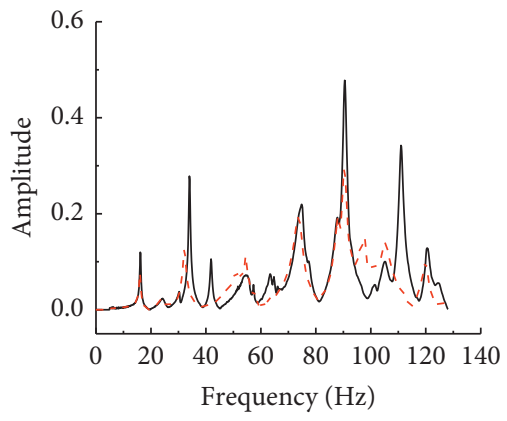

- Case $1 \mathrm{DA}$ of location D - - - Case 4 DA of location D

(d)

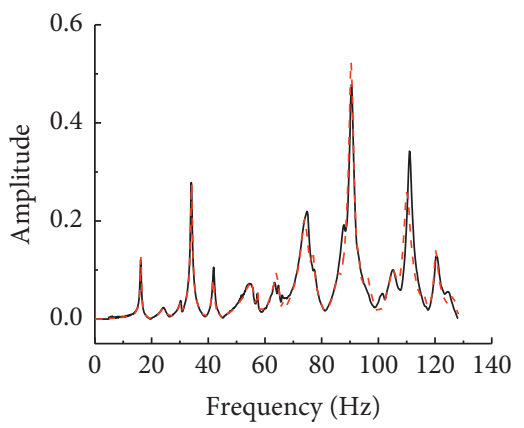

- Case $1 \mathrm{DA}$ of location D - - Case 2 DA of location D

(b)

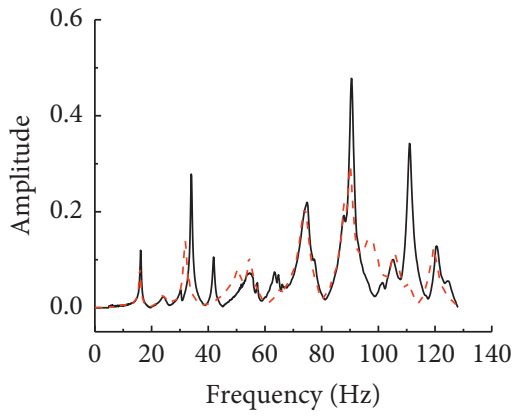

- Case 1 DA of location D
- - Case 5 DA of location D

(e)

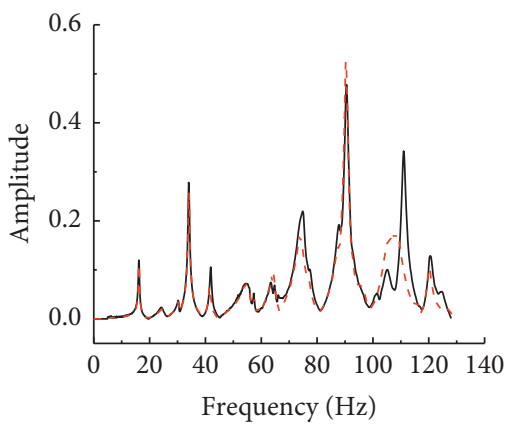

- Case $1 \mathrm{DA}$ of location D - -- Case 3 DA of location D

(c)

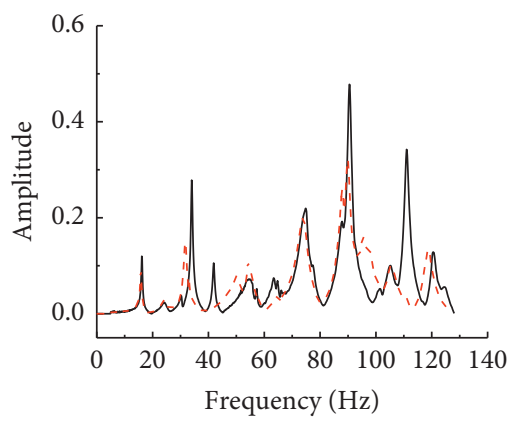

- Case 1 DA of location D
- - Case 6 DA of location D

(f)

Figure 11: Continued. 


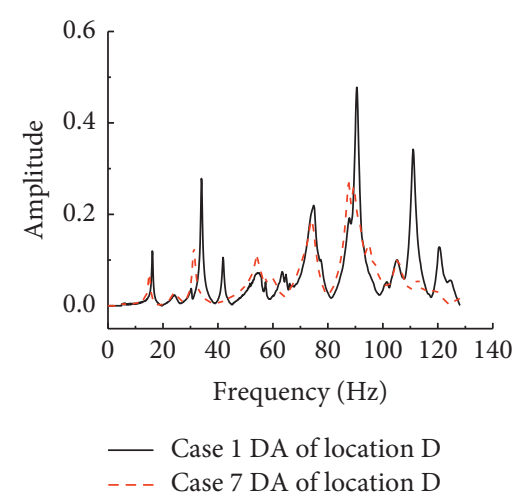

(g)

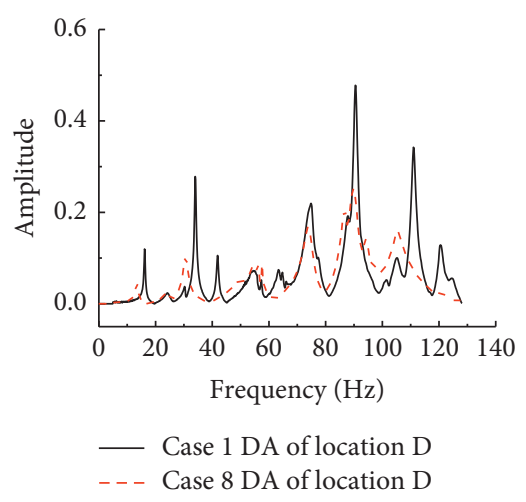

(h)

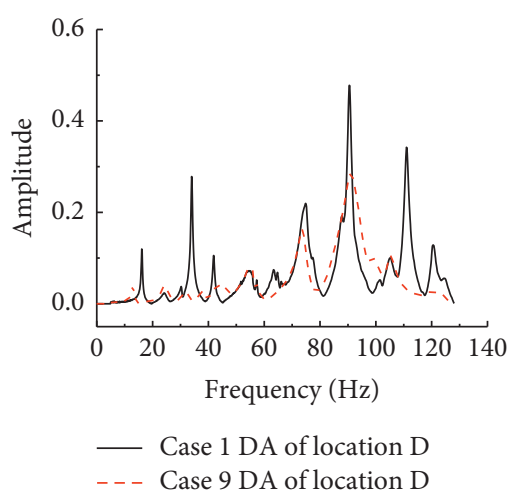

(i)

Figure 11: Comparison of DA of driving point D under different cases, (a) 1 vs. 1 ; (b) 1 vs. 2; (c) 1 vs. 3 ; (d) 1 vs. 4 ; (e) 1 vs. 5 ; (f) 1 vs. 6 ; (g) 1 vs. 7 ; (h) 1 vs. 8 ; (i) 1 vs. 9 .

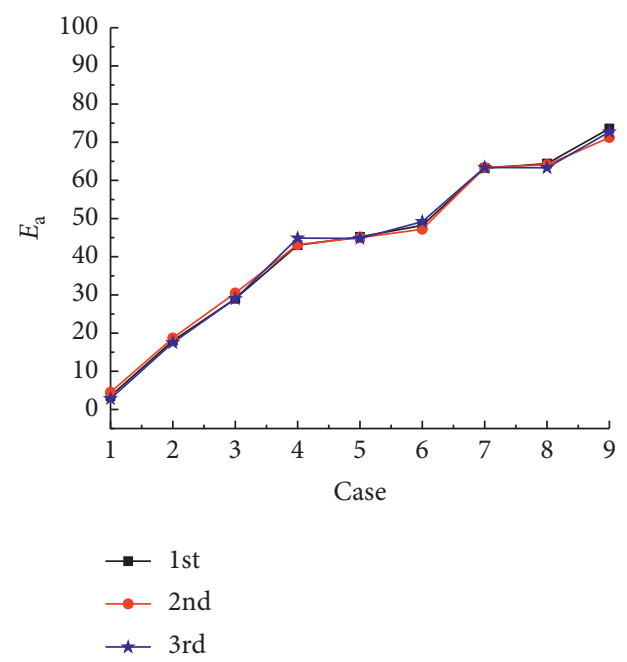

(a)

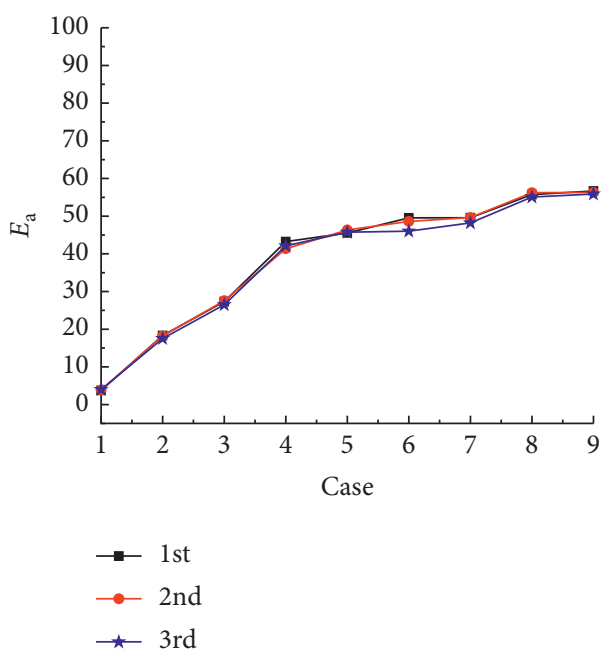

(b)

Figure 12: $E_{\mathrm{a}}$ for various cases: (a) driving point A; (b) driving point D.

order vibration modes is small since the low-order modal reacts to the overall macroscopic property and is not sensitive to the local damage. When the frequency is higher than $60 \mathrm{~Hz}$, the difference of DA between the damaged and undamaged case is significant, even though the damage is small. It is because the higher mode reflects the local information so that it is sensitive to the local damage. Therefore, when using the $E_{\mathrm{a}}$ algorithm, the analysis frequency should reach the modal order that can fully reflect the structural dynamic response. The interval of frequency for calculating the $E_{\mathrm{a}}$ is specified between $0 \mathrm{~Hz}$ to $128 \mathrm{~Hz}$ in the test. The DAs of the nine cases of driving point $\mathrm{D}$ are shown in Figure 11, which has similar responses as in Figure 10.

It was tapped three times under every case. According to the experimental data, the results of $E_{\mathrm{a}}$ for various cases are listed in Figure 12.

Figure 12 shows the value of $E_{\mathrm{a}}$ is positively correlated with the severity of delamination, that is, $E_{\mathrm{a}}$ increases with the increase of the severity. In the test, the results of tapings for the same case are all smaller than 5\%, which means that the random error of hammer taping location will have a slight effect.

5.3. Discussion. The average value of $E_{\mathrm{a}}$ of three taps are shown in Table 3. The fundamental frequency reduction [38] $E_{\omega 1}$ and modal assurance criterion (MAC) [18] are also listed in Table 3 for comparison. The $E_{\omega 1}$ can be calculated by

$$
E_{\omega 1}=\left|\frac{\omega_{1}^{u}-\omega_{1}^{d}}{\omega_{1}^{u}}\right| \times 100 \%,
$$

where $\omega_{1}^{u}$ is the undamaged fundamental frequency of the SSGS and $\omega_{1}^{d}$ is the fundamental frequency of damaged SSGS. The $i$ th predamage mode shape is $\left\{\varphi_{i}^{u}\right\}$, and the $i$ th postdamage one is $\left\{\varphi_{i}^{d}\right\}$; then, MAC of $\left\{\varphi_{i}^{u}\right\}$ and $\left\{\varphi_{i}^{d}\right\}$ is

$$
\operatorname{MAC}\left(\left\{\phi_{i}^{u}\right\},\left\{\phi_{i}^{d}\right\}\right)=\frac{\left(\left|\left\{\phi_{i}^{u}\right\}^{\mathrm{T}} \cdot\left\{\phi_{i}^{d}\right\}\right|^{2}\right)}{\left(\left\{\phi_{i}^{u}\right\}^{\mathrm{T}} \cdot\left\{\phi_{i}^{u}\right\} \cdot\left\{\phi_{i}^{d}\right\}^{\mathrm{T}} \cdot\left\{\phi_{i}^{d}\right\}\right)}
$$


TABle 3: $E_{\mathrm{a}}, E_{\omega 1}$, and MAC.

\begin{tabular}{|c|c|c|c|c|c|c|c|c|c|c|}
\hline & & 1 & 2 & 3 & 4 & 5 & 6 & 7 & 8 & 9 \\
\hline $\begin{array}{l}\text { Delam } \\
(\%)\end{array}$ & n severity & 0 & 6.39 & 12.78 & 19.16 & 25.55 & 31.94 & 38.33 & 48.61 & 58.89 \\
\hline$E_{\mathrm{a}} / \%$ & g point $\mathrm{A}$ ) & 3.60 & 18.10 & 29.50 & 43.74 & 45.03 & 48.25 & 63.38 & 63.96 & 72.52 \\
\hline$E_{\mathrm{a}} / \%$ & g point $\mathrm{D}$ ) & 3.87 & 18.02 & 27.12 & 42.24 & 46.03 & 48.05 & 49.14 & 55.68 & 56.29 \\
\hline$E_{\omega 1} / \%$ & & 0 & 0.13 & 0.79 & 1.67 & 2.64 & 2.69 & 6.94 & 18.13 & 20.33 \\
\hline \multirow{3}{*}{ MAC } & 1st order & 1 & 0.98 & 0.97 & 0.97 & 0.97 & 0.77 & 0.16 & 0.35 & 0.12 \\
\hline & 2nd order & 1 & 0.99 & 0.99 & 0.98 & 0.98 & 0.39 & 0.45 & 0.32 & 0.27 \\
\hline & 3 rd order & 1 & 0.91 & 0.87 & 0.44 & 0.36 & 0.43 & 0.36 & 0.19 & 0.18 \\
\hline
\end{tabular}

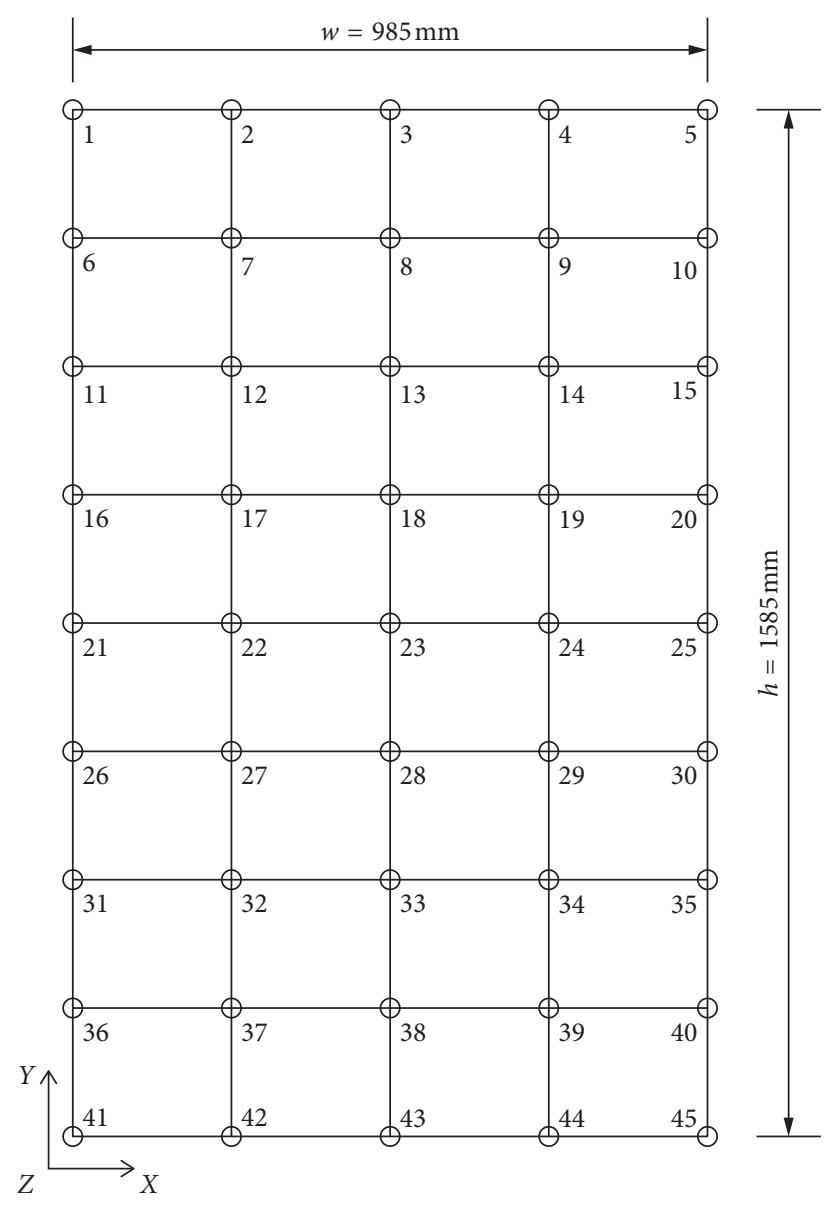

FIGURE 13: Driving points in experimental modal analysis (unit: $\mathrm{mm}$ ).

For each case, the natural frequency and mode shapes are obtained by experimental modal analysis. In the modal experiment, the glass panel is divided into 32 cells and 45 tap points, as shown in Figure 13. The eigensystem realization algorithm (ERA) $[39,40]$ is used to identify the natural frequencies and mode shapes. The identified fundamental frequencies are shown in Figure 14. The identified first mode shapes were shown in Figure 15.

In Figure 15, colors represent the relative amplitude of the mode shapes with colors from purple to green showing the decrease of the amplitude. A block is installed at the bottom of the glass curtain wall panel. While the block helped supporting the vertical gravity of the panel, and it also restricted the horizontal displacement. Therefore, the mode shape of case 1 is unsymmetrical and the mode amplitude of the top was larger than that of the bottom. The block also effectively restricted all of other cases which cause the mode amplitude of bottom was relative less. It can be seen that the differences of mode shapes between case 1, case 2, and case 3 were small. For case 4 and case 5 , the change in the mode shapes was obvious, but the MAC of the first mode shape was still almost unchanged. In fact, MAC of the first two modes was larger than 0.95 until the delamination severity is $25.55 \%$ (case 5 ). The low sensitivity of fundamental frequency and mode shape shifts to delamination required either in very precise measurements or more serious 


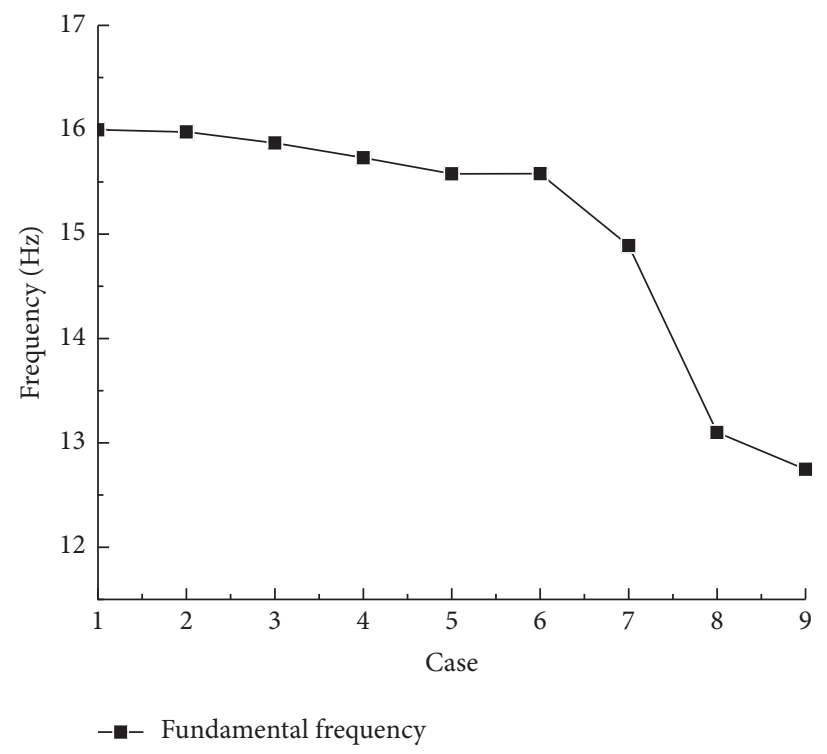

Figure 14: The change of fundamental frequency.

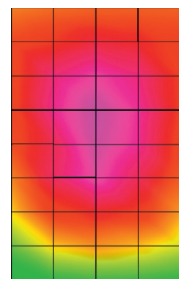

(a)

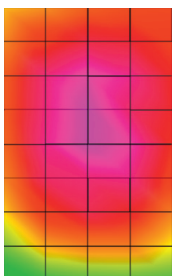

(b)

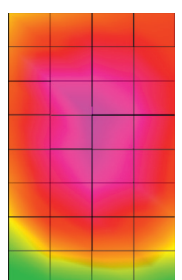

(c)

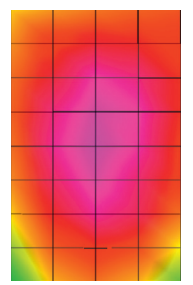

(d)

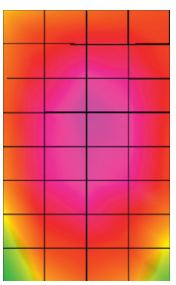

(e)

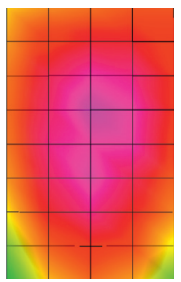

(f)

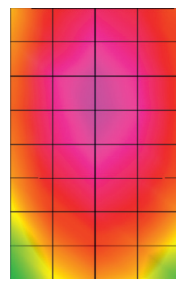

(g)

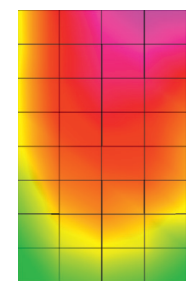

(h)

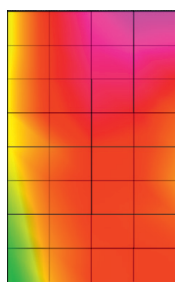

(i)

Figure 15: First mode shapes for various cases: (a) Case 1; (b) Case 2; (c) Case 3; (d) Case 4; (e) Case 5; (f) Case 6; (g) Case 7; (h) Case 8; (i) Case 9.

damages $[17,35]$. However, the MAC of the 3rd mode was 0.91 for case 2 , which was relative sensitive. In addition, it can be seen from Figure 15 that the change of fundamental frequency is small until case 6 , that is, the fundamental frequency reduction $E_{\omega 1}$ is less than $5 \%$ until the delamination severity is around $32 \%$.

From Figures 10 and 11, together with Table 3, it can be seen that the $E_{\mathrm{a}}$ leads to increase with the increase of damage severity. For case 2, the delamination severity is only $6.39 \%$, and the $E_{\mathrm{a}}$ is $18.10 \%$ and $18.02 \%$ for driving points $\mathrm{A}$ and $\mathrm{D}$, respectively. When comparing the $E_{\mathrm{a}}$ of location $\mathrm{A}$ and location $\mathrm{D}$ in Table 3 , it is clear that the $E_{\mathrm{a}}$ is very sensitive to delamination, even though delamination is small and the distance between the driving points and the delamination will also change the detected $E_{\mathrm{a}}$. The difference between the $E_{\mathrm{a}}$ of driving points $\mathrm{A}$ and $\mathrm{D}$ increases as the damage severity increases. Especially, for case 7 to 9 , the $E_{\mathrm{a}}$ of location $\mathrm{A}$ and location $\mathrm{D}$ are significantly different. The comparisons between the $E_{\mathrm{a}}$ of location $\mathrm{A}$ and location $\mathrm{D}$ indicates that even if the $E_{\mathrm{a}}$ is very sensitive to both delamination severity and locations, it is more sensitive to severity than to locations. In addition, even if the relative location between the driving point and delamination location is very far, the changes of $E_{\mathrm{a}}$ is significant for small delamination. The high sensitivity of DA is a result of that fact that the higher natural frequencies and mode shapes are more sensitive to small and local delamination. The DA includes more than 10 mode shapes responses in the test; therefore, the small delamination would induce significant changes of DA. For practical applications, if both delamination location and severity are needed, two or more DA locations may be required and other damage index may be needed to be developed in 
addition to $E_{\mathrm{a}}$ for the accurate measurements on both parameters.

According to the results of test, when the $E_{\mathrm{a}}$ is larger than $10 \%$, the existence of sealants delamination can be identified with confidence. In practical application, the measured natural frequency will change because of the environmental influence [41]. It is difficult to work out damage identification when the damage index is less than $5 \%$. Therefore, $E_{\omega 1}$ and MAC of the lower mode shapes are only suitable for damage identification of large delamination. To get higher modal shape, it needs relative long time to finish much more point taps. However, only one point is required to measure DA. Therefore, it is more convenient for engineering applications to detect the damages by DA.

\section{Conclusions}

Based on the difference of predamage and postdamage DA, a new delamination index, which calculates the relative accumulation difference of predamage and postdamage DA, is proposed to identify the delamination of the sealant in SSGS. Theoretical and experimental results show that

(1) To measure DA, only one acceleration sensor and a rubber hammer are required, so the test operation is extremely simple. The relative accumulative difference of DA increases with the increase of the delamination of the sealant. The relative accumulation difference of DA is very sensitive to delamination because it includes much information of higher modes; thus, it is applicative to identify the delamination of sealant in SSGS. It can be seen that the sealants have delamination when the $E_{\mathrm{a}}$ is larger than $10 \%$.

(2) The location of acceleration sensor installment will influence the value of DA. Usually, the relative optimal place to install the sensor is at the intersection of the long side and the quarter of the short side of the glass panel where it would cause symmetric and antisymmetric mode shapes. To decrease the effect of the error of hammer impact location, the impact hammer taps in the direction of the long side, and the tapping point should be controlled within $3 \mathrm{~cm}$ far from the sensor.

(3) The fundamental frequency reduction is suitable to identify relatively large delamination. The MAC of higher mode shape is sensitive to local damage and can be used to delamination identification of SSGS, but it will spend relative long time.

In the future, more research studies are needed to analyse the performance of this method with the changes of temperatures, detect small delamination using the relative accumulation difference of DA under different sizes of panels and different damage sites, combine other damage index to identify the damage locations, and perform actual field testing.

\section{Data Availability}

The data used to support the findings of this study are available from the corresponding author upon request.

\section{Conflicts of Interest}

The authors declare that they have no conflicts of interest.

\section{Acknowledgments}

The authors are very grateful for the support of the fund. This study was supported by the Foundation of National Key R\&D Program during the 13th Five-year Plan Period, Grant no. 2016YFC0700805.

\section{References}

[1] C. Efstathiades, C. C. Baniotopoulos, P. Nazarko, L. Ziemianski, and G. E. Stavroulakis, "Application of neural networks for the structural health monitoring in curtain-wall systems," Engineering Structures, vol. 29, no. 12, pp. 34753484, 2007.

[2] W. Lu, B. Huang, K. M. Mosalam, and S. Chen, "Experimental evaluation of a glass curtain wall of a tall building," Earthquake Engineering \& Structural Dynamics, vol. 45, no. 7, pp. 1185-1205, 2016.

[3] K.-H. Kim, "A comparative life cycle assessment of a transparent composite façade system and a glass curtain wall system," Energy and Buildings, vol. 43, no. 12, pp. 3436-3445, 2011.

[4] M. M. El Shami and K. S. Kandeel, "Structural behaviour of glass folded plate curtain walls," The IES Journal Part A: Civil \& Structural Engineering, vol. 4, no. 2, pp. 69-78, 2011.

[5] T. F. O'Connor, "Design considerations in structural sealant glazing," in Science and Technology of Glazing Systems, vol. 17, pp. 5-21, ASTM Special Technical Publication, West Conshohocken, PA, USA, 1989.

[6] Q. Xu, Y. F. Tang, and M. M. Wang, "Comparative study about on-site testing methods for silicone structural sealant," China Build Water Poof, vol. 16, pp. 22-25, 2011, in Chinese.

[7] Z. C. Tan, "Methods of glue's inspection for existing building curtain wall," Industry Construction, vol. 43, pp. 651-654, 2013, in Chinese.

[8] B. Mojškerc, T. Kek, and J. Grum, "Pulse-echo ultrasonic testing of sealants bonded joints in glass façades," Journal. of Mechanical. Engineering, vol. 62, no. 3, pp. 147-155, 2016.

[9] Y. Staudt, C. Odenbreit, and J. Schneider, "Failure behaviour of silicone adhesive in bonded connections with simple geometry," International Journal of Adhesion and Adhesives, vol. 82, pp. 126-138, 2018.

[10] S.-J. Jang, H.-D. Yun, and M.-S. Lee, "Effects of stiffening sealant thickness on the structural performance of structural silicone glazing (SSG) sealant connections in curtain wall systems," Archives of Civil and Mechanical Engineering, vol. 17, no. 1, pp. 65-74, 2017.

[11] G. H. Huang, "A summary of test methods for structural glue of in-service building glass curtain wall," Sichuan Building Material, vol. 40, pp. 140-141, 2014, in Chinese.

[12] Y. K. Sun, "Study on weather resistance and on-site inspection technology of silicone rubber for glass curtain wall," Master's degree, China Building Materials Research Institute, Beijing, China, 2018, in Chinese.

[13] R. J. Zhu, Y. Y. Chen, and J. W. Liu, "Current situation of safety detection technology on existing glass curtain wall," China Building Material Technology, vol. 27, pp. 1-3, 2018, in Chinese.

[14] X. B. Hong, Y. Liu, P. S. Lin, and W. Xu, "Interfacial adhesionstrength detection of structural silicone sealant for hidden 
frame-supported glass curtain wall based on nonlinear ultrasonic lamb wave," Journal of Aerospace Engineering, vol. 31, Article ID 04018047, 2018.

[15] X. Hong, Y. Liu, Y. Liufu, and P. Lin, "Debonding detection in hidden frame supported glass curtain walls using the nonlinear ultrasonic modulation method with piezoceramic transducers," Sensors, vol. 18, no. 7, p. 2094, 2018.

[16] X. Hong, J. Lin, Y. Liu, and W. Xu, “Active thermal sensing for bonding structure damage detection of hidden frame glass curtain wall," Sensors, vol. 18, no. 11, p. 3594, 2018.

[17] S. W. Doebling, C. R. Farrar, M. B. Prime, and D. W. Shevitz, "Damage identification and health monitoring of structural and mechanical systems from changes in their vibration characteristics: a literature review," Shock \& Vibration Digest, vol. 30, pp. 2043-2049, 1996.

[18] C. R. Farrar and D. A. Jauregui, "Comparative study of damage identification algorithms applied to a bridge: I. experiment," Smart Materials and Structures, vol. 7, no. 5, pp. 704-719, 1998.

[19] E. Khanmirza, N. Khaji, and V. J. Majd, "Model updating of multistory shear buildings for simultaneous identification of mass, stiffness and damping matrices using two different softcomputing methods," Expert Systems with Applications, vol. 38, no. 5, pp. 5320-5329, 2011.

[20] G. Sha, M. Radzieński, M. Cao, and W. Ostachowicz, "A novel method for single and multiple damage detection in beams using relative natural frequency changes," Mechanical Systems and Signal Processing, vol. 132, pp. 335-352, 2019.

[21] L. Wang, S. T. Lie, and Y. Zhang, "Damage detection using frequency shift path," Mechanical Systems and Signal Processing, vol. 66-67, pp. 298-313, 2016.

[22] H. R. Ahmadi, F. Daneshjoo, and N. Khaji, "New damage indices and algorithm based on square time-frequency distribution for damage detection in concrete piers of railroad bridges," Structural Control and Health Monitoring, vol. 22, no. 1, pp. 91-106, 2015.

[23] A. Iqbal, A. Faten, E. Alaa, and Z. Feng, "Damage detection in one- and two-dimensional structures using residual error method," Journal of Sound and Vibration, vol. 462, Article ID 114908, 2019.

[24] H. Mao, W. Tang, Y. Huang et al., "The construction and comparison of damage detection index based on the nonlinear output frequency response function and experimental analysis," Journal of Sound and Vibration, vol. 427, pp. 82-94, 2018.

[25] A. M. Memari, X. Chen, P. A. Kremer, and R. A. Behr, "Prediction of seismic failure of silicone sealant in two-sided structural sealant glazing systems," Journal of Architecture Engineering, vol. 18, no. 1, pp. 6-26, 2012.

[26] H. Puga, B. A. Olmos, L. Olmos, J. M. Jara, and M. Jara, "Damage assessment of curtain wall glass," Journal of Physics: Conference Series, vol. 628, Article ID 012052, 2015.

[27] A. Carolina, C. Nicola, M. Giuseppe, A. Bonati, A. Franco, and A. Occhiuzzi, "Experimental and numerical investigation of cyclic response of a glass curtain wall for seismic performance assessment," Construction and Building Material, vol. 187, pp. 596-609, 2018.

[28] H. Xu, J. Yang, and X. E. Wang, "Application of back propagation neural network on debonding prediction of glass curtain walls with concealed frame," Journal of the Chinese Ceramic Society, vol. 8, pp. 1073-1079, 2019, in Chinese.

[29] X. Liu, Y. Bao, Y. Song, and Y. Qiu, "Safety evaluation of glass curtain walls by using dynamic method," China Civil Engineering Journal, vol. 42, pp. 11-15, 2009, in Chinese.
[30] X.-G. Liu and Y.-W. Bao, "Safety evaluation for frame supported glass curtain wall based on modal frequency change," Shenyang University Technology, vol. 33, no. 5, pp. 595-600, 2011, in Chinese.

[31] Y.-h. Miao, Yinjie, G.-j. Cai, and J.-z. Gu, "New measurement technology of structural silicone sealant in hidden frame supported glass curtain wall based on FFT power spectrum," in Prooceedings of the International Conference on Computer Distributed Control and Intelligent Environmental Monitoring, pp. 92-95, IEEE Computer Society, Changsha, China, February 2011.

[32] Z. H. Fang and W. Q. Luo, "Study on the damage detection of full-scale frame-concealed glass curtain-walls based on modal curvature," Value Engineering, vol. 36, pp. 89-93, 2017, in Chinese.

[33] Z. Huang, M. Xie, H. Song, and Y. Du, "Modal analysis related safety-state evaluation of hidden frame supported glass curtain wall," Journal of Building Engineering, vol. 20, pp. 671678, 2018.

[34] Z. Huang, M. Xie, J. Zhao, Y. Du, and H.-k. Song, "Rapid evaluation of safety-state in hidden-frame supported glass curtain walls using remote vibration measurement," Journal of Building Engineering, vol. 19, pp. 91-97, 2018.

[35] Z. Huang, M. Xie, C. Chen, Y. Du, and J. Zhao, "Engineering application of a safety-state evaluation model for hidden frame-supported glass curtain walls based on remote vibration," Journal of Build Engineering, vol. 26, Article ID 100915, 2019.

[36] J. Zhao and J. T. DeWolf, "Sensitivity study for vibrational parameters used in damage detection," Journal of Structural Engineering, vol. 125, no. 4, pp. 410-416, 1999.

[37] R. W. Clough and J. Penzien, Dynamics of Structural, Computers and Structures, Berkeley, CA, USA, 2nd edition, 2003.

[38] P. C. Karninski, "The approximate location of damage through the analysis of natural frequencies with artificial neural networks," Proceedings of the Institution of Mechanical Engineers, Part E: Journal of Process Mechanical Engineering, vol. 209, pp. 117-123, 1995.

[39] J.-N. Juang and R. S. Pappa, "An eigensystem realization algorithm for modal parameter identification and model reduction," Journal of Guidance, Control, and Dynamics, vol. 8, no. 5, pp. 620-627, 1985.

[40] X.-M. Yang, T.-H. Yi, C.-X. Qu, H.-N. Li, and H. Liu, "Automated eigensystem realization algorithm for operational modal identification of bridge structures," Journal of Aerospace Engineering, vol. 32, Article ID 04018148, 2019.

[41] J. M. Montalvão, E. Silva, and A. J. M. Aráujo Gomes, "Experimental dynamic analysis of cracked free-free beams," Experimental Mechanics, vol. 30, pp. 20-25, 1990. 